\title{
TRABALHO E JUVENTUDE NO CONTEXTO CONTEMPORÂNEO: REFLEXÕES INTRODUTÓRIAS
}

\author{
WORK AND YOUTH IN THE CONTEMPORARY CONTEXT: INTRODUCTORY \\ REFLECTIONS
}

\author{
Anabella Pavão da Silva ${ }^{1}$ \\ Neide Aparecida de Souza Lehfeld ${ }^{2}$
}

\begin{abstract}
Resumo: Historicamente, a categoria trabalho apresenta distintas configurações. No capitalismo, problematiza-se o sentido do trabalho para a classe dominante e, como esta compreende a classe trabalhadora, formatando reflexões acerca dos antagonismos que caracterizam a sociedade de classes no tempo do capital. Neste processo de determinações históricas que rebaixam os trabalhadores à condição de mercadorias, traçou-se um recorte deste estudo para a juventude - categoria social, política, cultural e econômica que enfrenta as contradições deste tempo no que se refere à sua relação no mundo do trabalho. Diante esta problemática, forma-se a hipótese de que o trabalho se configura em um direito competitivo e não em uma garantia constitucional, violando a proteção de milhões de jovens. Diante o exposto, propomos uma reflexão introdutória acerca do panorama do mundo do trabalho para a juventude brasileira. O estudo se funda no método dialético-crítico, com análise bibliográfica e documental. O objetivo geral é o de refletir as implicações do trabalho contemporâneo no cotidiano de jovens brasileiros. Quanto aos objetivos específicos, almejamos descortinar o atual cenário do trabalho no Brasil; e refletir a relação da crise no mundo do trabalho com a marginalização da juventude brasileira do direito ao trabalho.
\end{abstract}

Palavras-chave: Juventude; Mundo do Trabalho; Capitalismo; Metamorfoses do Trabalho.

\begin{abstract}
Historically, the work category has different configurations. In capitalism, the meaning of labor is questioned for the ruling class and, as it comprises the working class, shaping reflections on the antagonisms that characterize class society in the time of capital. In this process of historical determinations that demean workers to the condition of goods, a study was drawn from this study for the youth - social, political, cultural and economic category that faces the contradictions of this time regarding their relation in the world of work. Faced with this problem, it is hypothesized that work is a competitive right and not a constitutional guarantee, violating the protection of millions of young people. Given the above, we propose an introductory reflection about the panorama of the world of work for Brazilian youth. The study is based on the dialectical-critical method, with bibliographic and documentary analysis. The general objective is to reflect the implications of contemporary work in the daily lives of young Brazilians. As for the specific objectives, we aim to unveil the current work scenario in Brazil; and to reflect the relationship of the crisis in the world of work with the marginalization of Brazilian youth from the right to work.
\end{abstract}

Key words: Youth; World of Work; Capitalism; Metamorphoses of Work.

\section{INTRODUÇÃO}

Historicamente, a categoria trabalho apresenta distintas configurações que apontam em sentido negativo para os mais pobres, fundada na perspectiva do castigo pelo trabalho forçado, no esforço e mérito individual ou na condição de exploração para a riqueza de poucos. Este trabalho dá ênfase à terceira possibilidade.

Ao se pensar o trabalho no capitalismo, problematiza-se a necessidade de pensar como se constituem as relações sociais e de produção. O sentido do trabalho para a classe dominante e, 
como esta compreende a classe trabalhadora, formatam reflexões acerca dos antagonismos que caracterizam a sociedade de classes no tempo do capital.

A partir da compreensão da categoria trabalho, poderemos compreender, a partir do pensamento marxiano, sobre a sociedade e as relações estabelecidas em diversos contextos sociais, políticos, econômicos, culturais e históricos, com ênfase nas transformações que vêm reconfigurando a sociedade do trabalho neste século.

O valor do trabalho no capitalismo também nos desafia a pensar as contradições deste sistema ao qual estamos submetidos há mais de duzentos anos. O valor do trabalho em modos de produção anteriores tinha outro significado, outra importância. No capital, seu sentido se configura para o preço da mão-de-obra que produz a mercadoria, o custo da produção, custo final da mercadoria e tempo de trabalho em todo o processo produtivo para chegar à conclusão de quanto será possível lucrar e quanto precisará ser utilizado para investir na continuidade da produção.

Neste processo de determinações históricas que rebaixam os trabalhadores à condição de mercadorias - mão-de-obra barata, substituível a qualquer momento, traçou-se um recorte deste estudo para a juventude, categoria social, política, cultural e econômica que enfrenta as contradições deste tempo no que se refere à sua relação no mundo do trabalho.

Diante esta problemática, afirma-se que o exército de reserva está acima da capacidade de gerência pelo sistema capitalista, isto é, existem mais pessoas buscando trabalho que ofertas de vagas que atendam plenamente estas pessoas. Diante esta crise no mundo do trabalho, os jovens, pelas exigências de experiência e conhecimentos específicos, não conseguem a primeira oportunidade, ficando marginalizados do direito ao trabalho e a renda. Sob esta assertiva, forma-se a hipótese de o trabalho se configura em um direito em competição e não uma garantia constitucional, violando a proteção de milhões de jovens.

Neste sentido, jovens, de classes sociais distintas, percebem oportunidades diferenciadas de inserção em espaços de trabalhos que ofertam condições de crescimento profissional e ascensão social e econômica. Ou ainda, percebem a ausência de oportunidades, recorrendo à informalidade, a trabalhos precários ou mesmo à criminalidade (SILVA: 2016).

Diante o exposto, apresenta-se neste texto, fundada no método dialético-crítico, uma análise bibliográfica e documental acerca da juventude e mundo do trabalho, com os objetivos de: apresentar três vertentes teóricas que analisam o sentido do trabalho na vida social e humana; descortinar o atual cenário do trabalho no Brasil; e refletir a relação da crise no mundo do trabalho com a marginalização da juventude brasileira do direito ao trabalho.

Neste sentido, este artigo é dividido em duas seções temáticas: na primeira analisaremos três correntes teóricas que discutem os sentidos do trabalho para a vida social dos sujeitos: a corrente medieval punitiva que reconfigura o sentido festivo e enobrecedor do trabalho; a corrente moderna que considera o trabalho como vocação divina, devendo o homem agir com esforço e dedicação sem se distrair com futilidades; e a vertente marxista que centraliza o trabalho na formação humana em cenário contraditório de disputas entre ricos e pobres sob o regime de exploração e baixo assalariamento.

A segunda seção discute as atuais configurações do mundo do trabalho a partir de referenciais teóricos e dados oficiais sobre o trabalho brasileiro, destacando as suas implicações no público 
jovem que enfrenta a realidade da exigência de experiência em uma fase da vida em que tudo está começando.

\title{
1 AS VERTENTES DA CATEGORIA TRABALHO: PUNIÇÃO, VOCAÇÃO E EX- PLORAÇÃO
}

Refletir o trabalho na sociedade capitalista nos desafia a compreender a complexidade de sua concepção e compreensão, considerando as transformações históricas e as tentativas de renovar a sua perspectiva ao longo do tempo. Traçamos para este estudo, três vertentes consideradas fundamentais para pensar as transformações na concepção desta categoria social, econômica, política, cultural e histórica.

Bonzatto (1998) traça um resgate histórico o qual aponta que o trabalho já possuiu uma visão festiva, de solidariedade, de sobrevivência coletiva e união. Pensemos as festas de colheita em tempos históricos anteriores, a produção para susbsistência e a união de grupos para a produção voltada para o autossustento. Neste sentido, emerge no trabalho a ideia de enobrecimento, amadurecimento e responsabilidade, que, a partir da idade média, ganha um novo desenho: da punição, tortura e da dor.

\begin{abstract}
No fim da Idade Média, o antigo sonho do alquimista de fabricar um homúnculo em laboratório tomou pouco a pouco a forma da criação de robôs para trabalharem em vez do homem e da educação do homem para trabalhar ao seu lado. Esta nova atitude perante a atividade produtiva reflete-se na introdução de uma nova palavra. Tripaliare significava "torturar sobre o trepalium", mencionado no século VI como uma armação construída por três troncos, suplício que substituiu o da cruz no mundo cristão. No século XII, a palavra trabalho significava uma experiência dolorosa. Foi preciso esperar até o século XVI para se poder utilizar a palavra trabalho em vez de obra ou de labor. À obra (poiesis) do homem artista e livre, ao labor (poneros) do homem pressionado por outro ou pela natureza, acrescentou-se então o trabalho ao ritmo da máquina. Seguidamente, a palavra trabalhador deslocou o seu sentido para agricultor e operário. No fim do século XIX, os três últimos termos mal se distinguiam entre si (ILLICH: 1976, apud BONZATTO: 1998, p. 2).
\end{abstract}

A fala de Illich (1976) descreve a negatividade que sentido do trabalho ganhou a partir de sua utilização como forma de castigo e de proporcionar dor e sofrimento àqueles condenados por alguma atitude considerada ilegal ou ainda, para reforçar o trabalho na conotação do servir, da submissão e da inferioridade.

Estes sentidos foram persistindo no tempo e no espaço, mesmo com as revoluções que pulverizaram o modo de produção feudal, inaugurando novos momentos para as relações políticas, econômicas e sociais a partir do mercantilismo e da ascensão do comércio e maior poder da classe burguesa.

As reformas religiosas também foram fundamentais para a construção de um novo sentido do trabalho. Para Sanson (2014), a partir de Lutero e Calvino, que o trabalho ganha novas configurações - a vocação, o qual todos os seres humanos são dotados para exercerem o trabalho durante a vida e o combate à preguiça e o trabalho como atividade que traz recompensas.

A partir destas lógicas, a visão do trabalho na vida cotidiana humana recebe um contorno religioso, na proposta de que ele dignifica os homens e que o trabalhador é o ser que mais se apro- 
xima da imagem divina, já que, segundo o texto bíblico, Deus criou o mundo (ou seja, trabalhou arduamente) em seis dias e descansou no sétimo (SANSON: 2014).

Com a dissolução dos últimos traços do regime feudal, instaura-se o capitalismo, com a ascensão política da classe burguesa na esfera pública, transformando o contexto social e também o trabalho. As fábricas, as cidades e a tecnologia passaram a fazer parte da sociedade europeia do século XVIII, estendendo influência para outros continentes que viviam a realidade de serem colônias. O trabalho se torna assalariado, o que fortalece a concepção de recompensa e de valorização por uma ação bem desempenhada, acentuando a relação do trabalho com a aproximação ao divino.

Weber (2004) busca compreender a relação da religião com a ascensão do capitalismo. As igrejas protestantes na Europa Ocidental e América do Norte estavam a desempenhar grande influência na vida social humana, consolidando o ideal do trabalho como caminho para o progresso e para a salvação divina. A interpretação weberiana traz à tona o ideal do trabalho no combate ao ócio, sendo este o obstáculo para o progresso e a salvação, segundo o protestantismo. Desta forma, o discurso do pecado caminha para reforçar em cada pessoa da proibição de realizar prazeres, diversões e o ócio, voltando a vida somente para o trabalho, pois o pecado, mata.

O homem, por sua queda no estado de pecado, perdeu por inteiro toda a capacidade de sua vontade para qualquer bem espiritual que o leve à salvação. Tanto que um homem natural, estando totalmente afastado desse bem e morto no pecado, não é capaz, por seu próprio esforço, de converter-se ou de preparar-se para tanto (WEBER: 2004, p. 91).

Para Weber (2004), o discurso do pecado e o seu combate pelo trabalho como a única atividade que desenvolve e aproxima os sujeitos de Deus, levou o desenvolvimento mais acentuado do capitalismo em países e regiões de predominância protestante. Este discurso se reflete até os nossos tempos por meios das igrejas evangélicas, principalmente as neopentecostais. Eis para Max Weber, a formação do espírito capitalista a partir da ética protestante.

Assim, o trabalho, segundo a ética protestante (WEBER: 2004), corresponde a uma obrigação determinada por Deus direto aos Homens e é só por meio desta atividade que estes poderiam viver sem pecados, respeitando ainda a naturalidade entre as classes sociais. Ricos e pobres existem por providência divina e esta se reproduz no sistema que, mesmo desigual, ainda sim é naturalmente atribuído por força divina.

Observem que o trabalho, antes solidário, que trazia união, se transforma em castigo e punição e, ainda com traços históricos de volta para a vocação, obrigação e salvação, emergindo ainda a ideia do esforço e do mérito. A partir destas características aqui apresentadas de forma sucinta, partimos para a reflexão do trabalho enquanto exploração.

Em sua trajetória intelectual e política, Marx (2013) pensava o trabalho tanto na perspectiva do capitalismo, quanto em um cenário no qual toda a sociedade se encontraria emancipada da exploração e das opressões da atual ordem societária.

Primeiramente, é importante destacar a posição filosófica materialista do pensador alemão. Marx (2013) defendia a ideia de que todas as sociedades, cada qual em um momento histórico distinto, mas não fragmentado no tempo e no espaço, construiu suas relações sociais e as capacidades de sobrevivência por meio da produção da vida material - necessária à manutenção das necessidades humanas. 
O homem, com o passar do tempo, foi aprendendo a lidar com a natureza e a dominá-la. Construiu saberes, habilidades e potencialidades de produzir tudo aquilo que pudesse proporcionar uma vida mais confortável e cada vez mais moderna. O desenvolvimento humano através do trabalho, configura uma sociedade ativa, que se desenvolve de forma desigual e injusta na contradição entre a acumulação de riqueza por poucos com a consequência do empobrecimento da maioria dos trabalhadores.

Segundo o pensamento crítico, introduzido por Karl Marx e aprimorado por pensadores posteriores, o trabalho é a categoria fundante do ser social (LUKÁCS: 2012). Isto é, os Homens se elevam da simples condição biológica e orgânica à de ser social, desenvolvendo suas múltiplas dimensões - social, cultural, política, econômica, emocional e subjetiva por meio do trabalho, sendo esta atividade a que transforma os Homens e se transforma de acordo com a evolução da atividade humana.

O trabalho conforme Marx é a base fundamental para que o ser humano se constituísse como ser social, superando a esfera do ser dominado pela natureza para o ser que pensa e a transforma para garantir sua existência. Desse modo, o trabalho assume o caráter mediador da relação homem e natureza, ao mesmo tempo em que transforma a natureza, transforma o próprio homem (AMARAL: 2014, p. 1-2).

O trabalho, para Marx (2013), ganha a importância de categoria complexa que realiza as mediações entre o homem e a natureza. Quanto mais nós soubermos utilizar os recursos naturais para a nossa existência, mais domínio teremos sobre a natureza, mais habilidosos seremos, mais a nossa mente criativa se desenvolve.

A produção de meios de subsistência, para Marx (2013), eleva o desenvolvimento do raciocínio e da consciência das pessoas, levando-os, intencionalmente, a produzir aquilo que obterá uma utilidade no cotidiano dela, como a confecção de agasalhos para o frio, roupas leves para tempos mais quentes, comida para que não passemos fome, telefones celulares cada vez mais modernos para ampliar e facilitar a comunicação, dentre inúmeros outros exemplos. Em outras palavras, o trabalho humaniza as pessoas, elevando-as da mera condição biológica para a extensão de ser social em sua plena complexidade historicamente determinada (SILVA: 2016).

Falando em mudanças na produção pela elevação criativa, é por meio do trabalho, que as pessoas aprimoram suas capacidades criativas e habilidades nos meios de produção. Este aprimoramento, leva a sociedade, ao longo da história a avançar nos recursos tecnológicos que passam a fazer parte da nossa vida, se tornando importantes para a nossa existência. "Além dos atos de trabalho, a vida social contém uma enorme variedade de atividades voltadas para atender às necessidades que brotam do desenvolvimento das relações do homem entre si.” (LESSA: 2012, p. 25), transformando a si mesmo.

"O trabalho é, antes de tudo, um processo entre homem e a natureza, processo este em que o homem, por sua própria ação, medeia, regula e controla seu metabolismo com a natureza" (MARX: 2013, p. 255).

A perspectiva marxiana apresenta um sentido mais complexo do trabalho entre os seres humanos, dada a nossa condição de seres racionais, ou seja, que pensam, planejam, criam, executam ações para uma finalidade estabelecida. O trabalho em Karl Marx segue a perspectiva ontológica 
do ser social. A ontologia seria o estudo e a reflexão acerca da natureza, da existência e do desenvolvimento do ser (LESSA: 2012).

A diferença do sentido do trabalho humano para o trabalho de outros seres, segundo Marx (2013), está na capacidade das pessoas idealizarem o resultado final daquilo que elas desenvolverão no processo produtivo e aprimorarem a produção durante o seu processo.

Pressupomos o trabalho numa forma em que ele diz respeito unicamente ao homem. Uma aranha executa operações semelhantes às do tecelão, e uma abelha envergonha muitos arquitetos com estrutura de sua colmeia. Porém, o que desde o início distingue o pior arquiteto da melhor abelha é o fato de que primeiro tem a colmeia em sua mente antes de construí-la com a cera. No final do processo de trabalho, chega-se a um resultado que já estava presente na representação do trabalhador no início do processo, portanto, um resultado que já existia idealmente (MARX: 2013, p. 255-256).

Para o processo produtivo acontecer, é necessário que os meios de produção sejam apropriados para tal: o espaço precisa ter uma estrutura mínima, maquinários, ferramentas, matéria-prima, quantidade de trabalhadores suficientes, salários, condições de trabalho salubres, planejamento, tempo de trabalho, custo da produção, custo da mercadoria, margem de lucro, investimento, liderança, capacitações, estar em local de fácil acesso ou promover o acesso dos trabalhadores quando a localização assim exigir.

Os meios de produção constituem-se dos objetos de trabalho e dos meios de trabalho. Os meios de trabalho incluem tanto os elementos que são precondições essenciais para o funcionamento do processo de trabalho, embora com ele se relacionem indiretamente (canais, estradas, entre outros), quanto os elementos através dos quais o trabalho se exerce sobre seu objeto, como as ferramentas e as máquinas (COLMÁN; DALA POLA: 2009, p. 2).

Conforme a produção se moderniza, as ferramentas e máquinas também avançam. Em todo processo produtivo, deve haver a transformação das condições, dos meios e dos objetos de trabalho, tendo em vista que a demanda se torna mais exigente. Neste interim, ao invés da produção simplesmente satisfazer as nossas necessidades humanas, ela se transforma em possibilidade de enriquecimento.

Para Colmán e Dala Pola (2009), em cada modo de produção - escravista, feudal e capitalista, o processo produtivo tinha um sentido e uma característica própria. No sistema capitalista, a produção é pensada por Karl Marx por meio da categoria valor - "o valor enquanto forma social do produto do trabalho" (COLMÁN; DALA POLA: 2009, p. 3).

Assim, para Marx (2013), o trabalho no capitalismo desconfigura a real necessidade da produção: que seria a de proporcionar acesso igualitário e universal de todos aos bens de consumo importantes para as necessidades humanas. A classe burguesa viu nas necessidades humanas um campo fértil para enriquecerem ainda mais, transformando produtos e trabalhadores em mercadorias, o qual o produto deve chegar à perfeição, e o trabalhador em uma condição de explorado e descartável a qualquer momento.

Neste sentido, o capitalismo inaugura uma nova fase na história da vida material, tornando-a muito mais complexa e dinâmica em comparação a tempos históricos anteriores. O modo de produção capitalista, além de metamorfosear o sentido do trabalho e a concepção de trabalhador, 
apresenta uma nova forma de apropriação de mercadorias: a forma do consumidor e da sua busca pelo consumo.

Sobre as transformações no mundo do trabalho no tempo presente, mesmo com a modernização das relações de trabalho e todas as possibilidades para criar, produzir e comercializar mercadorias, observa-se um avanço da precarização e da liquidez da dinâmica e da permanência de trabalhadores nos processos produtivos.

Dentre inúmeras consequências negativas que as metamorfoses do trabalho (ANTUNES: 2011) nos coloca, destacam-se as consequências em nossa saúde mental - o sentimento de desvalorização, impotência, incapacidade ou mesmo a auto responsabilização pelos problemas e fracassos hoje existentes. Ao mesmo tempo que o trabalho traz a sensação de se sentir útil, produtivo, ativo em alguma tarefa, consigo vem os dessabores apontados nas linhas acima.

Antunes e Alves (2004) apresentam as novas formas de ser do trabalho, considerando, a partir da perspectiva da ontologia do ser social, as alterações que ocorreram na compreensão da categoria trabalho a partir do desenvolvimento perverso do sistema capitalista.

A concepção de trabalho compreende a totalidade dos assalariados, homens e mulheres que vivem da venda da sua força de trabalho, não se restringindo apenas aos trabalhadores manuais, incorporando também a totalidade do trabalho social, a totalidade do trabalho coletivo que vende sua força de trabalho como mercadoria em troca de salário.

Devemos indicar, desde logo, que a classe trabalhadora hoje compreende a totalidade dos assalariados, homens e mulheres que vivem da venda da sua força de trabalho - a classeque-vive-do-trabalho, conforme nossa denominação (Antunes, 1995 e 1999) - e que são despossuídos dos meios de produção. Mas ela vem presenciando um processo multiforme (ANTUNES; ALVES: 2004).

Este crescimento multiforme, flagela de diversas formas esta classe, que já sofre com a histórica exploração da classe burguesa. A multiformatação da categoria trabalho, indica o aparecimento de várias tendências, que, segundo os referidos autores, apresentamos a seguir:

1. Redução do proletariado industrial, fabril, tradicional, manual, estável e especializado;

2. Aumento do novo proletariado fabril e serviços;

3. Aumento significativo do trabalho feminino;

4. 4.Expansão dos assalariados médios no setor de serviços;

5. Crescente exclusão de jovens;

6. Exclusão dos trabalhadores considerados idosos pelo capital - 40 anos;

7. Expansão do terceiro setor;

8. Expansão do trabalho em domicílio;

9. Configuração do mundo do trabalho cada vez mais transnacional.

Dentre as tendências que redesenham o mundo do trabalho, o destaque será dado à juventude e seus desafios de se inserirem, se manterem ou de retornar ao mundo do trabalho, considerando ainda as diferenças de reflexões teóricas que pensam o trabalho ao longo do tempo. 


\section{TRABALHO E JUVENTUDE NO CENÁRIO CONTEMPORÂNEO}

Vive-se um momento paradoxal na garantia do acesso, permanência (no sentido do não desemprego), qualificação e dignidade de jovens no mundo do trabalho. As mudanças na base legal que oportuniza aos jovens maior tempo de estudo e inserção posterior ao trabalho ainda não são suficientes para garantir empregos e rendas de qualidade à esta população que busca a primeira oportunidade de ingresso e, posterior crescimento, em espaços sócio-ocupacionais.

Como um resultado de determinantes históricos, sociais e culturais, como já abordado, o trabalho se configurou como uma atividade de extrema importância para o desenvolvimento da vida humana. Sem trabalho, as pessoas não possuem o reconhecimento de cidadãos que percorrem o reto caminho do bem comum.

É comum ouvirmos a expressão "o trabalho dignifica o homem”, para inferir que a construção de um caráter digno, idôneo, íntegro, moralmente aceito se constitui por meio do acesso e permanência no trabalho. Esta assertiva empírica e histórica é discutível, considerando o contínuo desmonte da proteção ao trabalho e sua constante precarização, que atinge todas as pessoas, desde os mais jovens até os mais velhos, incluindo ainda aqueles que buscam a primeira oportunidade ou que já se aposentaram. O trabalho precarizado não dignifica nenhuma pessoa, ao contrário, expropria os sentidos humanos das pessoas, as alienam em seus espaços de sociabilidade, obstruí qualquer capacidade de reflexão crítica, as aprisiona em trabalhos sem perspectivas de crescimento, as adoece e ainda viola o direito à vida, seja por acidentes de trabalho, seja pelo suicídio.

Além deste aspecto, que interfere no caldo das sociedades, a busca precoce por trabalho, envolve vários aspectos da vida social de jovens. A busca pela independência, o acesso a bens de consumo, entretenimento, a utilização de rendimentos para a conquista de um status social que permitirá maiores laços de sociabilidades ou mesmo o auxílio na manutenção das necessidades humanas em seus lares, seja na ajuda aos pais ou em suas famílias já constituídas, com companheiras/ os e filhas/os.

A depender das condições objetivas de jovens em busca por trabalho, o resultado pode ser interessante ou devastador. Jovens da classe trabalhadora em níveis de pauperismo mais acentuados, desistem dos estudos para a inserção em ocupações que dificilmente oportunizará uma ascensão econômica e social. Este panorama quebra a ideia de que as oportunidades existem para todos, bastando aos jovens conquistá-las com seu esforço e mérito.

A meritocracia compreende uma construção ideológica da sociedade capitalista, com fundamento nas condições de vida da classe burguesa, que formatam a ideia de que qualquer pessoa pode atingir o topo do sucesso no mundo do trabalho, se dispor de força física, mental e suor para alcançar espaços que outros já atingiram. Só que esta concepção não leva em consideração os níveis acentuados de desigualdade e injustiça social que diferenciam a luta por espaço e o seu tranquilo acesso, a partir da condição de classe à qual ricos e pobres se inserem. Relacionar as condições e as oportunidades entre ricos e pobres, e entre muito ricos e muito pobres com a afirmação de que as elas estão dadas igualmente dadas para todos, é imoral e de uma total ausência de reflexão crítica e leitura de uma realidade contraditória e antagônica tecida no manto da injustiça social.

Além das desigualdades de oportunidades, a subjetividade humana também se diferencia entre uma pessoa e outra. Não podemos conceber a ideia de que todas as pessoas reagem ou lidam 
com a realidade da mesma forma. A subjetividade no pensamento crítico possui relação intrínseca com a vida material, objetiva e concreta, ou seja, ela pertence ao complexo processo de formação humana, a objetivação da vida humana constitui e é constituída pela subjetivação do ser social.

Quer dizer, Marx não considera o indivíduo humano apenas no seu caráter objetivo, determinado, mas em seu processo de autodeterminação. E é nesse processo de autoconstrução que se criam novas formas de objetivação, que possibilitam, por sua vez, novas formas de subjetivação (CHAGAS: 2013, p. 65).

As objetivações e subjetivações humanas se particularizam em cada sujeito individual e coletivo, levando-o a reações e ações distintas. Esta particularidade se constitui no processo de desenvolvimento da história de vida do sujeito e toda a bagagem que ele acumula ao longo de sua vida. Quando falamos em juventude, este debate necessita de maior intensidade, considerando a peculiar fase de desenvolvimento e os anseios que a fase jovem provoca aos sujeitos em seus contextos sociais.

Pois bem, para pensar a juventude e o mundo do trabalho, é importante destacarmos que esta população é expressiva no território brasileiro. O Brasil é um país que envelhece. Estudos de órgãos governamentais de pesquisa, como o Instituto Brasileiro de Geografia e Estatística (IBGE), apontam a redução na taxa de natalidade e o aumento da expectativa de vida da população. A pirâmide etária, que antes era extensa em sua base, se encurta, elevando-se do centro ao topo.

Somos uma nação jovem que, em menos de 50 anos se tornará um país mais idoso. A mudança na intensidade geracional da população brasileira não desqualifica, tampouco reduz a importância de pensar a juventude e o trabalho, pois, se considerarmos a importância do envelhecimento ativo e da qualidade de vida da população, esta deve (deveria) ser garantida pelas políticas de proteção social desde o nascimento da/o cidadã/o até a sua morte.

Segundo o IBGE (2018), a população jovem, compreendida entre os 15 aos 29 anos, apresentou a estimativa de 50.803.219 pessoas. Em 2014, de acordo com o DIEESE (2015), a população jovem, compreendida entre os 15 aos 29 anos estava estimativa em 52.538 .000 pessoas.

O próprio IBGE vem sinalizando a gradual redução da população jovem e o nivelamento da população idosa. Estima-se que, até em 2060, o Brasil terá mais de 33\% de sua população total, pessoas com mais de 60 anos. O Instituto ainda destaca que o Brasil continuará com taxas de crescimento populacional até 2047. A partir daí, haverá uma tendência no decréscimo da população brasileira, que atualmente, se encontra na faixa dos 209,9 milhões, segundo a projeção ${ }^{3}$ do IBGE para o primeiro semestre de 2019.

Dentre toda a população economicamente ativa, ou seja, que se encontram em idade para o trabalho, a juventude é a geração que mais concentra o índice de desempregados. Pompeu (2006) afirma que, considerando ser na juventude que se busca o primeiro emprego e, ao mesmo tempo, não se tem a devida experiência requerida pelas organizações contratadoras, consolida-se assim, a preponderância do desemprego entre a população jovem.

Silveira e Alvarenga (2018) ao analisarem as pesquisas trimestrais da Pesquisa Nacional por Amostra de Domicílios (PNAD), detectaram que falta trabalho, nas condições mais convencionais para mais de 27 milhões de pessoas, sendo que deste montante, 13 milhões se encontram desempregados, mas persistem na procura por trabalho, 6,5 milhões estão subocupados, ou seja, trabalham 
em jornadas inferiores a 40 horas/semanais e 8,1 milhões de pessoas que poderiam trabalhar, mas não trabalham, isto é, são pessoas com força de trabalho em potencial, mas se encontram fora do mercado por diversas razões, sendo elas, 4,8 milhões de desalentados, ou seja, que desistiram de procurar trabalho e 3,3 milhões que não trabalham por não possuir disponibilidade.

Os dados ainda retratam que $34,7 \%$ dos desempregados, são pessoas com idade entre 25 a 39 anos, a taxa maior apresentada, estando em segundo lugar, com 32,6\%, jovens de 18 a 24 anos e em terceiro lugar, adultos com idade entre 40 a 59 anos, representando $22,2 \%$. Os demais dados representam adolescentes de 14 a 17 anos $-7,8 \%$ e pessoas idosas a partir dos 60 anos $-2,8 \%$ (IBGE: 2018).

Os dados de 2018 se elevam em 2019. Dados do IBGE divulgados pelo Portal G1 em abril de 2019, a partir de análise de Silveira e Alvarenga (2019) ilustram a elevação do desemprego no Brasil no primeiro trimestre. São 13,4 milhões de desempregados no país, a maior taxa desde maio de 2018. Destes mais de 13 milhões, 1,2 milhão se inserem na classificação de desocupados (aqueles sem trabalho, mas que não estão à busca dele). Para o IBGE, segundo Silveira e Alvarenga (2019), a queda do número de ocupados reflete as demissões de trabalhos temporários que se encerram entre dezembro e janeiro de cada ano.

Em dados gerais, no primeiro trimestre, 28,3 milhões se encontram fora de trabalhos convencionais, conforme explicado anteriormente. O IBGE a partir Silveira e Alvarenga (2019) vai chamá-los de pessoas subutilizadas, apresentando um aumento de 1,3 milhão de pessoas entre 2018 e 2019.

Gráfico 1 - Subutilização no Brasil

\section{Subutilização recorde no país}

em número de brasileiros

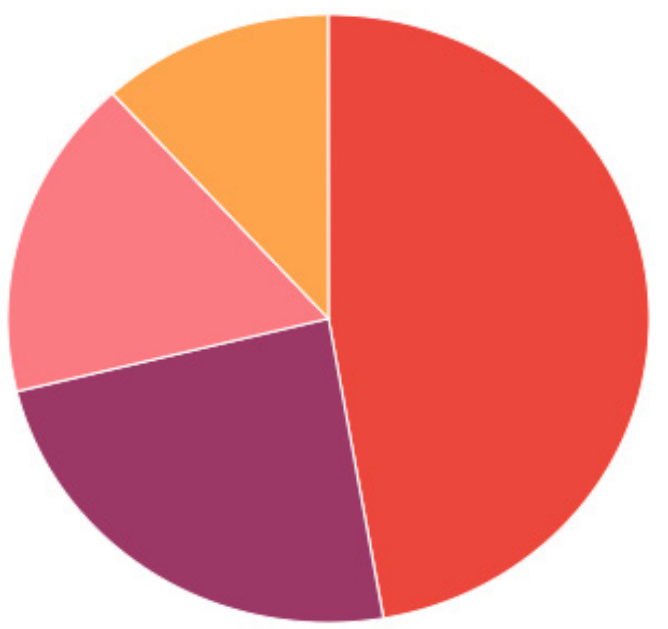

Desempregados: 13.387

Desalentadas: 4.843

Subocupados (que trabalham menos de $40 \mathrm{~h}$ por semana): 6.768 Fora da força de trabalho potencial: $\mathbf{3 . 3 2 6}$

Fonte: Silveira; Alvarenga, 2019. 
É importante destacar que, para a pessoa ser considerada desempregada, segundo as metodologias de coleta de dados das instâncias oficiais de pesquisa, ela precisa estar fora do mercado de trabalho e estar à procura de trabalho. Se esta mesma pessoa estiver sem trabalho e não procurando por ele, ela passa a ser considerada desocupada. Esta concepção de desocupação alimenta o estereótipo do sujeito que não trabalha, reforçando a moralidade e a dignidade somente pelo trabalho.

Como que, em um contexto plural como este apresentado, podemos inferir tão empiricamente que a juventude contemporânea não se interessa pelo trabalho, sendo que faltam oportunidades ou as que surgem são precarizadas e exploradoras? Juventude tem direito ao trabalho digno, à escolarização continuada e à qualificação profissional, que, mesmo inseridas no Estatuto da Juventude (BRASIL: 2013) não são garantidas com qualidade, integralidade de acesso universal à toda a população jovem brasileira.

Neste sentido, apontamos a diversidade de busca por estratégias de trabalho e emprego pelos jovens. Considerando a atual conjuntura de crise estrutural do capital (MÉSZÁROS: 2011), a elevação do desemprego e o distanciamento de boas perspectivas de melhoras deste cenário, 38\% dos jovens que se encontram fora do mercado formal de trabalho, recorrem à informalidade para alcançarem seus objetivos (PEREIRA: 2018, online). Estes objetivos se voltam para a socialização, amadurecimento, sentimento de utilidade, satisfação pessoal, sobrevivência ou independência.

A inserção do jovem no mercado de trabalho não define o indivíduo como adulto, mas define, justamente, a condição juvenil, pois possibilita ao jovem viver esta condição. Viver a condição jovem está baseado na possibilidade de aproveitar esse momento de maneira menos comprometida comparativamente ao adulto, vivendo situações de prazer e diversão antes que responsabilidades e encargos aumentem com a necessidade de cuidar da família e dos filhos (JEOLÁS; LIMA, 2002, p. 46-47).

Estes jovens, no discurso moral sobre o trabalho, podem até ser considerados desempregados, por se encontrarem à margem da formalidade, todavia, eles não se encontram desocupados, pois, mesmo não procurando trabalho, este percentual está realizando outras atividades em caráter informal, sejam atividades domésticas, de economia solidária, no âmbito de materiais recicláveis ou outras atividades, chamadas por "bicos".

Estes dados e provocações, reforçam a importância das reflexões de Antunes e Alves (2004), no que se refere às transformações no mundo do trabalho. Dentre os fenômenos que caracterizam o que os pensadores chamam de mutações do trabalho, apresenta-se a redução dos jovens no mundo do trabalho.

No Brasil, os jovens também enfrentam desafios no que se refere à inserção no mercado de trabalho. Segundo a Pesquisa Nacional por Amostra de Domicílios (PNAD), do Instituto Brasileiro de Geografia e Estatística (IBGE, 2011), o percentual de jovens entre 15 e 24 economicamente ativos, ou seja, que fazem parte do mercado de trabalho, diminuiu de 57,7\% em 2001 para 53,6\% em 2011 (GUIMARÃES; ALMEIDA: 2013, p. 09).

Esta redução se dá, principalmente, pela precarização da educação básica e da oferta, em muitos casos, de cursos de formação técnica que não contemplam os desejos ou mesmo os perfis de jovens para a realização de determinadas atividades. Quando há a oferta de formações consoantes às habilidades dos jovens, o custo do investimento para a inserção nos cursos impede os mesmos de ampliarem as possibilidades de inserção no mundo do trabalho. 
Esta realidade é um forte alvo dos julgamentos histórico-morais a respeito do trabalho. Quando o jovem se recusa ou não consegue bom desempenho em uma função que ele não possui perfil, emerge o discurso da preguiça, do desinteresse e da falta de adesão. Lutamos para que cada pessoa estude e trabalhe naquilo que mais gosta. Mesmo na era da precarização do trabalho, trabalhar em uma área de interesse traz um suspiro diante as dificuldades que enfrentamos.

Acentuar a ideia de que quem está sem emprego não pode escolher muito é acentuar uma violência moral e verbal em jovens que são julgados e culpabilizados pelas privações às quais vivem. É transferir os efeitos nocivos de um sistema injusto e desigual em uma população que não possui as mesmas oportunidades. O levantamento do IBGE de 2019 divulgado nos meios de comunicação aponta que, dentre o total de desempregados, jovens de 14 a 24 anos são os que mais sentem este fenômeno.

A primeira oportunidade não surge com facilidade ou nem surge para a geração juvenil que apresenta $28 \%$ da sua população sem trabalho. É mais de 1/4 dos jovens brasileiros, entre 18 a 29 anos, atualmente sem trabalho. São várias características que "justificam" as dificuldades dos jovens de conseguirem trabalho, como a baixa qualificação, a inexperiência ou a escolaridade.

Segundo o DIEESE (2015), o tempo médio de estudo destes jovens é pouco mais de 09 anos. Os dados também apontam que, alunos trabalhadores possuem maior tempo de estudo do que aqueles que somente estudam ou que só trabalham. Ou seja, alunos trabalhadores, associam o tempo de estudo à maior qualificação para o trabalho, movimentando maiores esforços para manter a rotina diária de trabalho e estudos, sem deixar que um compromisso interfira no outro.

Tabela 1 - Anos de estudos entre alunos trabalhadores, somente alunos e somente trabalhadores

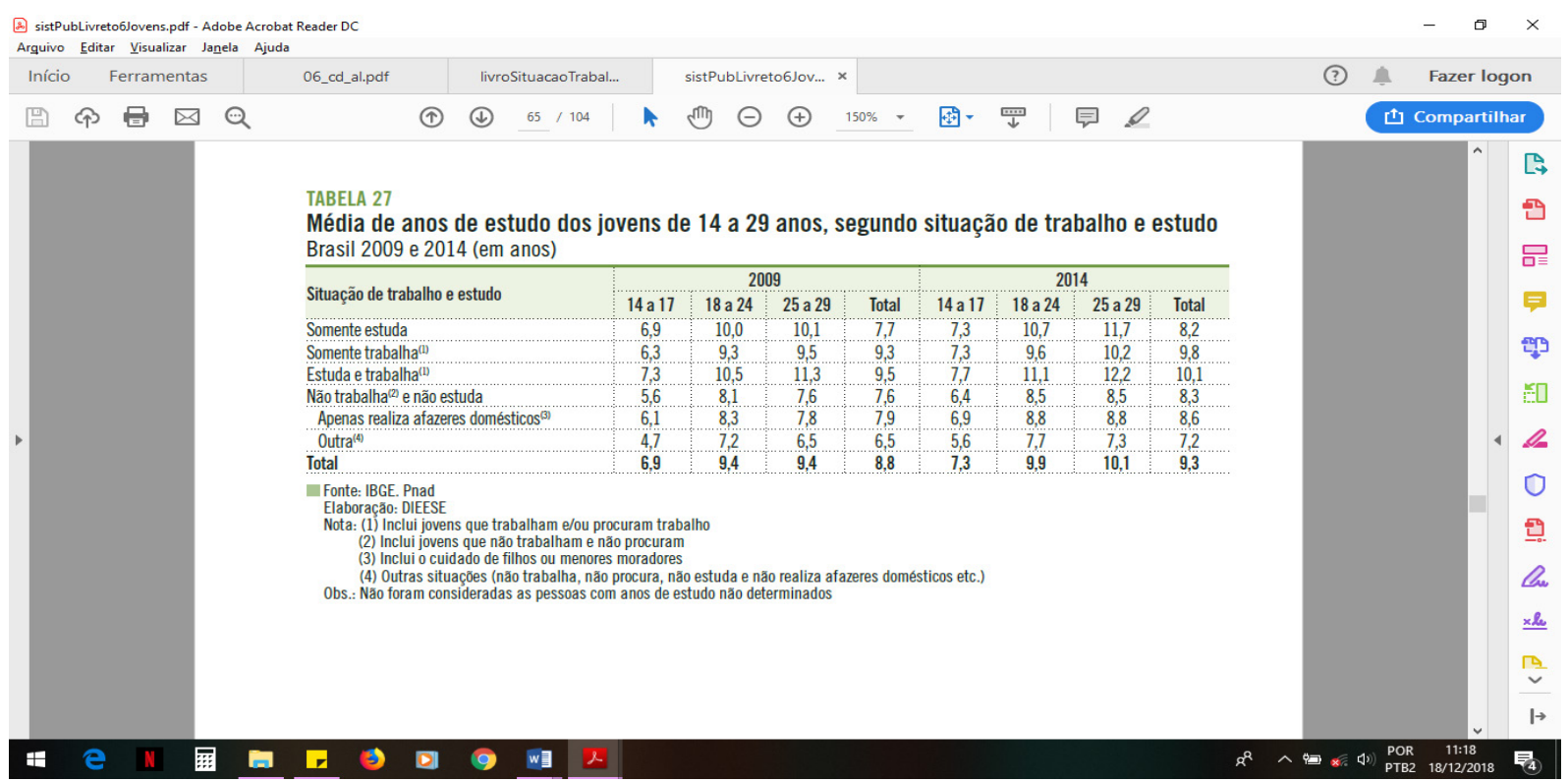

Fonte: DIEESE, 2015.

As transformações no ensino superior também indicam a dificuldade de inserção ou de permanência do jovem no mundo do trabalho. Observamos, atualmente um aumento no número de matrículas e redução no orçamento das Instituições de Ensino Superior (IES) públicas. Esta diver- 
gência entre a ampliação de vagas e redução no investimento, obstruí a permanência estudantil de jovens que não possuem recursos para se manterem na vida universitária, levando-os à desistência.

Quanto às IES privadas, a reconfiguração do estudante em cliente, precariza a formação em nome do lucro e do mercado financeiro. A educação superior privada mais atende à lógica mercantil e operacional que a de formação de profissionais qualificados, transformando-se em fábricas de diploma que pouco servem ao mercado; e quando serve é precário e ausente de qualidade.

Para Chauí (1999), a Universidade em sua configuração operacional surge da necessidade de reduzi-la ao aspecto econômico, focando estratégias de contratação e gestão financeira, deixando para segundo plano, o compromisso com a formação intelectual e de qualidade do corpo discente. A universidade operacional desmonta a qualidade formativa, precariza as relações de trabalho, o exercício da docência e o tripé - ensino, pesquisa e extensão e transforma os alunos em clientes. O resultado desta lógica é atender aos interesses do mercado, levando a juventude que ingressa na Universidade à uma selvagem competitividade por um emprego.

Regida por contratos de gestão, avaliada por índices de produtividade, calculada para ser
flexível, a universidade operacional está estruturada por estratégias e programas de eficácia
organizacional e, portanto, pela particularidade e instabilidade dos meios e dos objetivos.
Definida e estruturada por normas e padrões inteiramente alheios ao conhecimento e à
formação intelectual, está pulverizada em microrganizações que ocupam seus docentes e
curvam seus estudantes a exigências exteriores ao trabalho intelectual (CHAUÍ: 1999, p.
5).

Os resultados atuais dos Exames Nacionais de Desempenho dos Estudantes (ENADE) tem demonstrado que o sonho do diploma em nível universitário não é mais garantia de sucesso e de inserção rápida e permanente no mercado de trabalho. A democratização do acesso ao ensino superior não se faz com a devida qualidade e compromisso com a formação de profissionais competentes e intelectualizados. Ao mesmo tempo, as políticas de trabalho e renda para os jovens não acompanham as mudanças no perfil de jovens trabalhadores com formações em diversas áreas.

Para os jovens pobres, mesmo com a diplomação, ainda restam cargos precários, subalternos, com poucas ou nulas chances de crescimento. São poucos jovens que conseguem alcançar boas oportunidades de ascensão econômica e social. Precisamos avançar ainda mais no combate à desigualdade social e de oportunidades, visando oportunizar melhores oportunidades para estes jovens se alocarem com segurança e qualidade nos espaços sócio-ocupacionais.

Outra característica da relação dos jovens com o trabalho, a partir da realidade brasileira,
e que o Brasil não estruturou uma rede de proteção social que possibilitasse um período
de formação e preparação anterior ao trabalho para todos. Para muitos jovens das camadas
populares, as primeiras experiências já ocorrem desde a infância, como, por exemplo,
ajudar nas atividades domesticas ou fazer "bicos". No meio rural, o trabalho também
aparece desde cedo em alguns casos, como no plantio e na colheita de outros agricultores
ou no auxílio aos pais em suas atividades diárias. Essas são experiências que nem sempre
são consideradas como trabalho. Em geral, as famílias das camadas populares valorizam
essas atividades por diversos motivos: contribuem para a renda familiar, afastam os jovens
"da rua" e "forjam o caráter" deles (LEÃO; NONATO: 2014, p. 19).

Além desta realidade, vivemos um tempo histórico em que o atual governo sinaliza que se gasta muito em educação e que os jovens devem reduzir a ansiedade pelo ingresso ao ensino superior, priorizando a formação técnica, devido ao menor tempo de formação e necessidades do 
mercado. Em outras palavras, o Estado orienta a juventude a adequar os seus sonhos e desejos às necessidades do capital.

Os dados do DIEESE (2015) apontam que, os espaços que mais empregam jovens são, dentre outros, comércio e reparação $-23,7 \%$, indústria $-15 \%$ e setor agrícola $-11,1 \%$. Ainda segundo o Departamento, destes espaços, não são $100 \%$ as contratações formais. Existe a informalidade nestes espaços, que precarizam as condições de trabalho, esvaziando os direitos e a proteção da vida cotidiana destes jovens.

Entre os trabalhos formais, apenas 58,8\% dos jovens entre 14 a 29 anos contribuem com a previdência social. É um índice baixo, se considerarmos o direito à cobertura previdência de qualquer trabalhador. A forma de contratação, seja por bolsas de aprendizes, contratos de trabalho não celetistas, enfim, são espécies de formalização que fogem do aspecto previdenciário. A ausência desta cobertura precariza direitos trabalhistas como o de Fundo de Garantia por Tempo de Serviço (FGTS), seguro desemprego, ou mesmo, a longo prazo, o de se aposentar.

Sobre o perfil do desemprego, $51,1 \%$ do público são de mulheres, enquanto $48,9 \%$ são homens. Daqueles que ainda trabalham, o rendimento médio do homem é superior $(\mathrm{R} \$ 2464,00)$ ao da mulher (R\$ 1925,00), confirmando a desigualdade salarial por motivos de gênero. Elemento que a pesquisa não identifica o índice de desemprego envolvendo orientação sexual e identidade de gênero. Sem dúvidas, os resultados são ainda mais alarmantes quando analisamos por estes vieses.

Quanto à formalidade, segundo faixa etária e gênero, tanto nas faixas etárias compreendidas entre os 14 aos 17 anos, 18 a 24 anos e 25 a 29 anos, observa-se que os homens têm maiores chances de formalização de seus contratos de trabalho que as mulheres. Em dados gerais (14 a 29 anos), mais de 9 milhões de homens possuem vínculos formais no mercado, enquanto as mulheres somam pouco mais de 6,8 milhões (DIEESE: 2015).

As diferenças se mantem expressivas quando inserimos o eixo raça/etnia nos dados. Segundo o DIEESE (2015), jovens não negros (brancos, amarelos e indígenas) somam mais de 7,6 milhões de pessoas com vínculo formal de trabalho, enquanto os jovens negros somam 5,9 milhões. A pesquisa não traz o recorte de gênero associado ao de raça/etnia, mas, ainda há disparidades salariais devido à questão de gênero. Estas disparidades aumentam quando a questão de gênero se alia à questão étnica/racial. As mulheres latino-americanas ganham menos, mesmo que possuam um maior nível de instrução. Por meio de comparação simples dos salários médios, foi constatado que os homens ganham $10 \%$ a mais que as mulheres. Já quando a comparação envolve homens e mulheres com a mesma idade e nível de instrução, essa diferença sobe para $17 \%$. Da mesma forma, a população indígena e negra ganha em média $28 \%$ menos que a população branca de mesma idade e nível de instrução (BRASIL: 2015).

A diferença salarial étnica poderia ser reduzida em quase um quarto com a melhora dos níveis de instrução dessa população. Homens ganham mais que as mulheres em todas as faixas de idade, níveis de instrução, tipo de emprego ou de empresa. A disparidade é menor nas áreas rurais, em que as mulheres ganham, em média, o mesmo que os homens. A menor diferença salarial relacionada a gênero está na faixa mais jovem da população que possui nível universitário, sendo a defasagem mais baixa entre trabalhadores formais e mais alta entre aqueles que trabalham em pequenas empresas (BRASIL: 2015). 
Em termos de faixa etária, o levantamento do DIEESE (2015) aponta uma oscilação entre idade e formalização de contrato de trabalho. Dentre a população economicamente ativa jovem (PEA Jovem), mais de 33 milhões trabalham com carteira assinada. Destes, 3,7 milhões tem idade entre os 14 aos 17 anos, 16,3 milhões tem idade entre 18 a 24 anos e 12,9 milhões possuem idade entre 25 a 29 anos. A formalização se concentra entre os jovens de 18 a 24 anos, sendo que anterior a esta faixa etária e, posteriormente, às condições de formalização são menores. A média de permanência destes jovens em um mesmo trabalho é de 20 meses, com atenção especial aos jovens de 14 a 17 anos que permanecem em média, 7 meses no mesmo trabalho.

Quanto ao rendimento médio destes jovens, observa-se uma realidade de ordenados baixos e extremamente baixos, dificultando os alcances de objetivos e sonhos desta população que veem nos salários, possibilidades de desenvolvimento e status. É impossível compactuar com um ideal de trabalho que progride e salva, cujo dever é obrigatório para todo ser humano, conforme Weber (2004) problematizou, considerando que a realidade do mundo do trabalho e suas ofertas de salários levam jovens, adultos e idosos, em suas diversas características a viverem na pobreza, na miséria, na privação e no sonho da vida digna e de qualidade.

Tabela 2 - Rendimento médio dos jovens

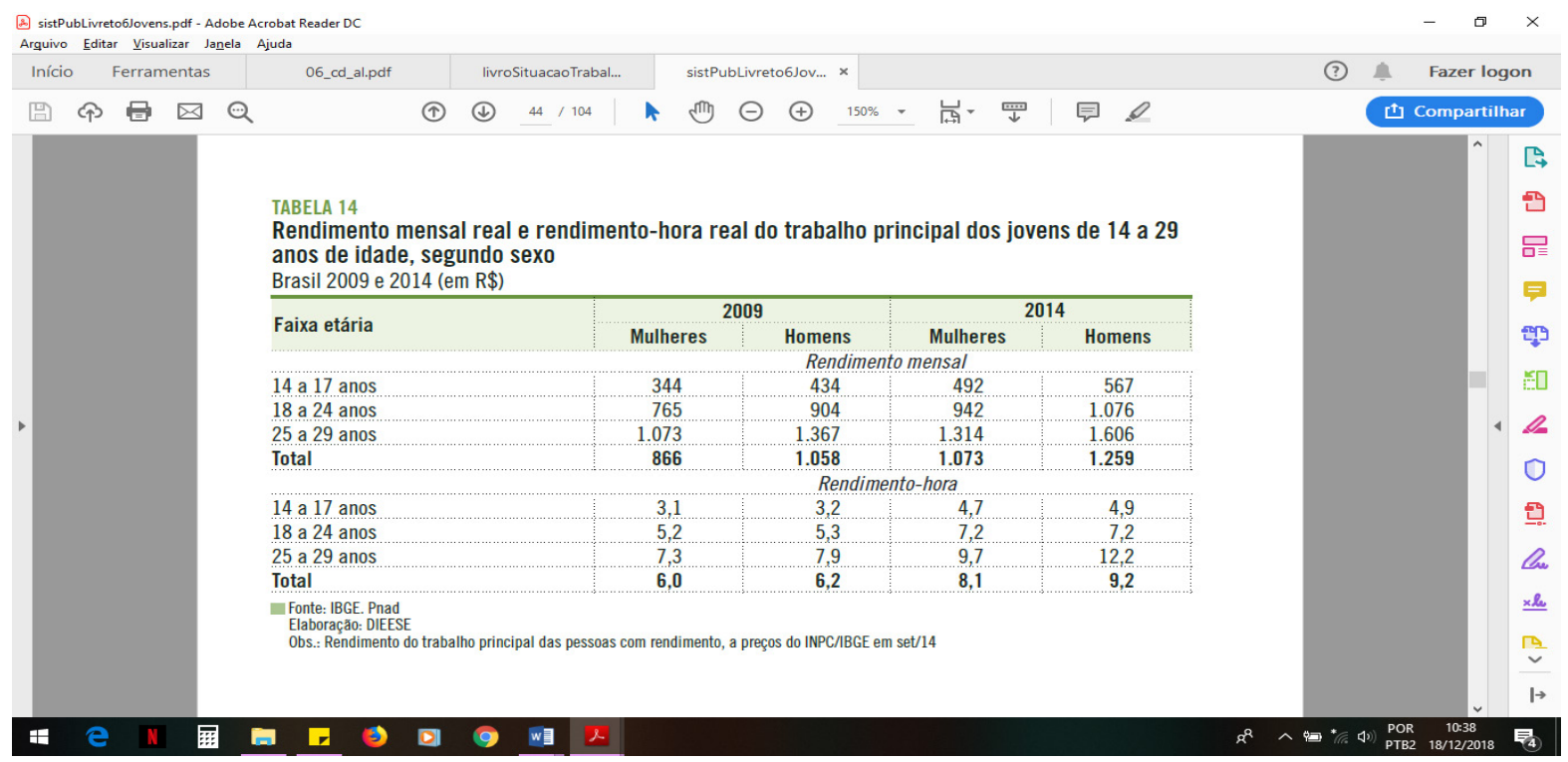

Fonte: DIEESE, 2015.

A tabela nos mostra algumas disparidades que nos impõem retomar as reflexões rapidamente. Além dos baixos salários que preocupam, principalmente a faixa etária dos 25 aos 29 anos, a diferença salarial entre homens e mulheres expressa a desigualdade de gênero e o machismo cristalizado no mundo do trabalho. Esta realidade é historicamente determinada pelas relações de subalternização entre homens e mulheres que sempre coloca à esta última, o espaço doméstico ou os mais precarizados espaços no mundo do trabalho (CISNE: 2012). A conquista feminina de espaço no mundo do trabalho ainda possui muitas lutas a travar, sendo a mais importante, o combate a extinção desta desigualdade que ainda inferioriza mulheres perante os homens nos mesmos cargos. 
Quanto aos baixos salários, somando à esta precária realidade, o desemprego acentuado e baixo tempo de permanência nos espaços de trabalho, Silva (2016) destaca a nivelação da inserção do jovem na criminalidade, principalmente em atividades delitivas que possam levar à ascensão econômica.

O estudo de Silva (2016) traz o relato de uma adolescente em liberdade assistida, cujo companheiro fora preso por tráfico de drogas. Relatos em entrevista, que, em uma determinada indústria, o seu companheiro ganhava um salário mensal de R $\$ 1400,00$ e, no tráfico, em 08 dias de atividades em "biqueiras", o mesmo acumulava um rendimento de R $\$ 9000,00$. Infelizmente, o fetiche do tráfico se tornou "o menino dos olhos" da juventude pobre, sendo que, uma parcela adentra a este espaço devido à conquista rápida e sem dispêndio de força física de um ganho significativo.

Enquanto a criminalidade se expande, as ações de proteção social do Estado sofrem com os constantes desmontes - seja na redução contínua do financiamento das políticas públicas, a seletividade cada vez maior, perda de direitos e burocratização do trabalho que distanciam os profissionais de suas demandas e contextos sociais. Além deste cenário, temos um índice de desemprego que não diminui, nivelando a pobreza, a desigualdade, a injustiça social e, consequentemente, a violência e a criminalidade.

Na questão do trabalho, emprego e renda, o Estado brasileiro oferece diretrizes e possibilidades de inserção juvenil no mundo do trabalho pela linha do aprendiz. Segundo o DIEESE (2015) cresceu o número de aprendizes em espaços sócio-ocupacionais diversos, de idade entre 14 a 29 anos. Considerando o Estatuto da Criança e do Adolescente (1990) e o Estatuto da Juventude (2013), o campo do aprendiz deveria ser uma abertura de portas para oportunidades de trabalho. Contudo, ainda observamos como os programas de aprendizes têm contribuído para a desvalorização da mão-de-obra do jovem e não em sua emancipação.

O setor de serviços é o que mais inserem jovens aprendizes, com carga horária entre 30 a 44 horas/semanais. O perfil de aprendizes varia entre homens e mulheres, negros e não negros e pessoas com deficiência e sem deficiência, que estejam ou não estudando.

A região sudeste, com $51 \%$ é a que mais desenvolve ações voltadas para a aprendizagem profissional (DIEESE: 2015). Os dados não apontam o rendimento médio de aprendizes, tampouco o tipo de pagamento efetuado, se é por salários ou bolsa de aprendizagem.

Enfim, existem inúmeros outros dados que poderíamos aqui analisar. Todavia, selecionamos os dados de pesquisas mais recentes publicadas e as informações que consideramos mais alarmantes e provocativas para algumas reflexões e breves análises. O que é importante frisar é a necessidade do Estado brasileiro se atentar mais à juventude brasileira, tanto na geração em desenvolvimento, quanto nas próximas que virão, considerando ainda a importância do envelhecimento populacional com qualidade e dignidade.

\section{CONSIDERAÇÕES FINAIS}

É inegável que a juventude vem, ao longo da história, enfrentando desafios em relação ao mundo do trabalho. Observamos a contradição que o mercado coloca quando exige experiências 
para determinadas faixas etárias. Experiências que nem sempre condizem com as oportunidades (ou ausência delas) alcançadas por jovens de diversas idades.

Esta breve reflexão teórica e crítica permitiu compreender que o capitalismo, dentre todas as suas contradições e selvagerias, não age diferente em face aos jovens da classe trabalhadora. Os espaços de trabalho, as dificuldades para o alcance de oportunidades promissoras e os trabalhos precários configuram o julgo da juventude trabalhadora que, por serem pobres, merecem somente trabalhos pobres. Isto é, para o jovem desempregado, qualquer trabalho está bom, pois o importante é se mostrar útil.

Por este parâmetro, é possível compreender o sentido do trabalho para as pessoas, que foge do sentido crítico da ação transformadora dos sujeitos, para o sentido moral da dignidade e da decência. As leituras realizadas, a cultura histórica a qual estamos submetidos nos leva a uma ideia deturpada de trabalho. O trabalho não dignifica o Homem, como se ouve no curso do tempo.

O trabalho é contraditório por transforma as pessoas, nos leva a relações sociais harmônicas e antagônicas, nos eleva a uma condição intelectual, econômica, social e material melhor e interessante, por outro lado, pode expropriar qualquer sentido humano, alienando-nos e acentuando a miséria humana e sua subalternidade.

Conformar-se com o trabalho precário, entendendo-o como a única possibilidade existente é reforçar a perspectiva funcionalista de que cada ser humano tem uma função pré-determinada, cabendo-nos aceitar o que está posto e fazer a nossa parte. Os dados analisados para este texto, nos provocam a reforçar a importância do estudo do trabalho, da sociedade capitalista e das relações humanas a partir da perspectiva crítica filosófica, descortinando as entrelinhas que se perfazem na vida cotidiana, transformando, permanentemente, as objetivações e subjetivações humanas.

Foi possível compreender ainda que, além da vida escolar e comunitária, o trabalho também se configura como espaço de relações sociais, de estreitar vínculos que possam ampliar a dimensão humana nas relações com o próximo e no autorreconhecimento em uma determinada sociedade, como ainda proporcionar espaços de crescimento e amadurecimento profissional. Aqui, concorda-se com o pensamento crítico marxiano quando este se refere ao trabalho como categoria fundante do ser social. Em outras palavras, o trabalho é a atividade transformadora e o espaço de relações sociais.

Ao mesmo tempo que o trabalho permite este movimento transformador, também é o espaço da exploração, desigualdade, alienação, de luta e de resistência. Os dados analisados permitiram considerar que a juventude pobre é que mais sofre no mundo do trabalho - seja pela dificuldade de inserção e/ou permanência, seja pela precarização das condições de trabalho e pelos níveis salariais.

$\mathrm{Na}$ contramão das contradições do mundo do trabalho, vê-se um Estado que pouco faz pelo jovem trabalhador. Os programas de aprendizagem profissional são importantes, mas não são suficientes para ampliar as vagas e as oportunidades de trabalho para os jovens em duas diversas complexidades. Necessita-se de maior investimento em políticas de trabalho, emprego e renda que respeitem a idade e as experiências do jovem, que identifiquem seus potenciais e dificuldades para que o seu amadurecimento se desenvolva com qualidade. Importante ainda considerar o jovem como cidadão de direitos e não como mão-de-obra barata, que transforma a aprendizagem em trabalho precário e, ao mesmo tempo, lucrativo e/ou conveniente. 
Este estudo ainda permitiu identificar a dificuldade de encontrar dados oficiais atualizados sobre a temática juventude e trabalho. As buscas por dados nos levaram a informações de 2009, 2010, 2012, 2014, 2015, 2018 e 2019. Os dados encontrados nos desafiam a ampliar a reflexão científica, problematizando in loco o atual retrato da juventude brasileira a partir da sua inserção na sociedade de classes no tempo do capital.

Em 2018, o IBGE apenas nos atualiza sobre a densidade populacional e as projeções para longo prazo. Por questão temporal e conjuntural, trabalhamos, obviamente com os dados de 2015, mas pensa-se que em três anos, o cenário sofreu alterações, considerando o momento político, econômico, social e cultural atual. O que o IBGE apresenta em 2019 ainda não é o suficiente para descortinar a essência que envolve a juventude brasileira no capitalismo.

Finalizamos esta reflexão, explicitando que procuramos apresentar sinteticamente alguns recortes para compreendermos melhor o panorama atual sobre a juventude brasileira e o mundo do trabalho. Estes recortes, sem dúvida, se configuram em outros estudos a serem realizados ou aprofundados, como a juventude e gênero, juventude e território urbano e rural, juventude negra e trabalho, juventude e classes sociais, juventude e diversidade sexual, juventude, trabalho e educação, juventude e educação profissionalizante, e assim por diante. Temos à frente uma gama de problemas que podem se transformar em relevantes objetos de estudos.

Desta forma, continuemos os estudos, na perspectiva crítica sobre este tema, para aprofundarmos os debates e as possibilidades de lutas por políticas públicas e garantia de direitos que compreendam o trabalho como uma necessidade humana e não como uma questão moral, e que a juventude tem tanto direito ao trabalho digno e decente como qualquer outro adulto mais experiente. Lutemos por um mundo do trabalho digno e que reduza as distâncias e as fronteiras da desigualdade e da injustiça social. Lutemos por uma sociedade do trabalho de fato transformadora, digna e, ousando dizer, emancipadora.

\section{NOTAS}

1 Assistente Social, Mestra e Doutoranda em Serviço Social pelo PPGSS da UNESP/Franca. Bolsista CAPES. Docente dos cursos de Serviço Social e Relações Internacionais da UNESP/Franca. Pesquisadora do GEPPIA (UNESP/Franca) e do Grupo PICO (UFTM). Contato: anabellapavao@gmail.com.

2 Assistente Social. Doutora em Serviço Social e Livre-docente. Professora titular do PPGSS da UNESP/ Franca.Contato: nlehfeld@unaerp.br.

3 Esta projeção aumenta em tempo real considerando os cálculos estatísticos para o crescimento populacional. Ver mais em https:/www.ibge.gov.br/apps/populacao/projecao/. Acesso em 29 mai. 2019.

\section{REFERÊNCIAS}

AMARAL, George. A categoria trabalho em Marx: alguns apontamentos sobre sua centralidade ontológica. In: SEMINÁRIO INTERNACIONAL TEORIA POLÍTICA DO SOCIALISMO, VI, 2014. Marília. Anais de Pesquisa. Marília, Unesp, 2014. Disponível em: http://www.marilia.unesp.br/Home/Eventos/2014/viseminariointernacionalteoriapoliticadosocialismo/a_categoria_georgea.pdf. Acesso em: 13 set. 2018.

ANTUNES, Ricardo; ALVES, Giovanni. As mutações no mundo do trabalho na era da mundialização do capital. Educação e Sociedade, Campinas, vol. 25, n. 87, p. 335 - 351, mai/ago, 2004. 
. Adeus ao trabalho? Ensaio sobre as metamorfoses e a centralidade no mundo do trabalho. 15 ed. São Paulo: Cortez, 2011.

BONZATTO, Eduardo Antônio. Tripalium: o trabalho como maldição, como crime e como punição. Direito em Foco, Amparo, 1998. Disponível em: http://www.unifia.edu.br/projetoRevista/artigos/direito/Direito em foco Tripalium.pdf. Acesso em: 29 mai. 2019.

BRASIL. Lei $\mathrm{n}^{\mathrm{o}}$ 12.852, de 5 de agosto de 2013. Institui o Estatuto da Juventude e dispõe sobre os direitos dos jovens, os princípios e diretrizes das políticas públicas de juventude e o Sistema Nacional de Juventude - SINAJUVE. Diário Oficial da União, Poder Legislativo, Brasília, DF, 6 ago. 2013. Disponível em: http:// www.planalto.gov.br/ccivil_03/_ato2011-2014/2013/lei/112852.htm. Acesso em: 29 mai. 2019.

BRASIL. Homens recebem salários 30\% maiores que as mulheres no Brasil. Observatório Brasil da igualdade de gênero. Disponível em: http://www.observatoriodegenero.gov.br/menu/noticias/homens-recebem-salarios-30-maiores-que-as-mulheres-no-brasil/. Acesso em: 05 out. 2018

; SECRETARIA de Políticas para Mulheres. Relatório da ONU Mulheres reconhece avanço das brasileiras no mundo do trabalho. Disponível em: http://www.spm.gov.br/noticias/relatorio-da-onu-mulheres-reconhece-avanco-das-brasileiras-no-mundo-do-trabalho. Acesso em: 05 out. 2018.

CHAGAS, Eduardo F. O pensamento de Marx sobre a subjetividade. Transformação, Marília, v. 36, n. 2, p. 63-84, mai./ago., 2013. Disponível em: http://www2.marilia.unesp.br/revistas/index.php/transformacao/ article/view/3099/2360. Acesso em: 05 out. 2018.

CHAUÍ, Marilena. A universidade operacional. Folha de São Paulo, Caderno Mais, mai. 1999. Disponível em: http://caf.fflch.usp.br/sites/caf.fflch.usp.br/files/arquivos/A_Universidade_Operacional.pdf. Acesso em: 20 mar. 2019.

CISNE, Mirla. Gênero, divisão sexual do trabalho e Serviço Social. São Paulo: Outras Expressões, 2012.

COLMÁN, Evaristo; DALA POLA, Karina. Trabalho em Marx e o Serviço Social. Serviço Social em Revista, Londrina, n. 2, jul - dez, 2009, p. 1 - 21. Disponível em: http://www.uel.br/revistas/ssrevista/ pdf/2009/2009 2/Artigo\%20evaristo.pdf. Acesso em: 13 set. 2018.

DIEESE. Anuário do sistema público de emprego, trabalho e renda: juventude. 2015. Livro 6. Disponível em: https://www.dieese.org.br/anuario/2015/sistPubLivreto6Jovens.pdf. Acesso em: 15 dez. 2018.

GUIMARÃES, Alexandre Queiroz; ALMEIDA, Mariana Eugênio. Os jovens e o mercado de trabalho: evolução e desafios da política de emprego no Brasil. Temas de Administração Pública, Araraquara, vol. 8, n. 2, 2013, p. 1 - 26. Disponível em: http://seer.fclar.unesp.br/temasadm/article/view/6845/4926. Acesso em: 06 out 2018 .

IBGE. Censo Demográfico 2010. Brasília: IBGE, 2010.

Pesquisa Nacional por Amostra de Domicílios 2012. Brasília, DF, 2013.

; FUNDAÇÃO GETÚLIO VARGAS. Economia brasileira em perspectiva. Brasília, DF: Ministério da Fazenda, 2014.

. Pesquisa Nacional por Amostra de Domicílios Contínua: trabalho e rendimento. Brasília, DF, nov. 2018. Disponível em: ftp://ftp.ibge.gov.br/Trabalho_e_Rendimento/Pesquisa_Nacional_por_Amostra_de Domicilios_continua/Trimestral/Quadro_Sintetico/2018/pnade_201803 trimestre quadroSintetico.pdf. Acesso em: 19 nov. 2018.

IBGE. Projeção da população do Brasil e das Unidades da Federação. Brasília, DF, 2019. Disponível em: https://www.ibge.gov.br/apps/populacao/projecao/. Acesso em 29 mai. 2019.

ILLICH, Ivan. A convivialidade. Lisboa: Europa América, 1976.

JEOLÁS, Leila Sollberger; LIMA, Maria Elena Melchiades Salvadego de Souza. Juventude e trabalho: entre fazer o que gosta e gostar do que faz. Revista Mediações, Londrina, v. 7, n. 2, jul./dez. 2002, p. 35-62. Disponível em: <http://www.uel.br/revistas/uel/index.php/mediacoes/article/view/9097>. Acesso em: 16 dez. 2018. 
LEÃO, Geraldo; NONATO, Symaira. Juventude e Trabalho. In: CORREA, Licinia Maria, et. al. Cadernos temáticos: juventude brasileira e ensino médio. Belo Horizonte: UFMG, 2014. Disponível em: $<\underline{\text { https:// }}$ observatoriodajuventude.ufmg.br/publication/view/colecao-cadernos-tematicos-juventude-e-trabalho/>. Acesso em: 15 dez. 2018.

LESSA, Sérgio. Mundo dos homens: trabalho e ser social. São Paulo: Instituto Lukács, 2012.

LUKÁCS, György. Para uma ontologia do ser social I. Tradução de Carlos Nelson Coutinho, Mario Duayer e Nélio Schneider. São Paulo: Boitempo, 2012.

MARX, Karl. Uma contribuição para a crítica da economia política. 1859. Disponível em: $<$ https://www. marxists.org/portugues/marx/1859/contcriteconpoli/index.htm>. Acesso em: 06 out. 2018.

2010a. Manuscritos econômico-filosóficos. Tradução de Jesus Ranieri. 4 reimp. São Paulo: Boitempo,

; ENGELS, Friedrich. O Manifesto do Partido Comunista. São Paulo: Boitempo, $2010 \mathrm{~b}$.

. O capital. Tradução de Rubens Enderle. São Paulo: Boitempo, 2013. Livro I.

MÉSZÁROS, István. A Crise Estrutural do Capital. 2a ed. São Paulo: Boitempo, 2011.

PEREIRA, Tiago. Informalidade e emprego precário estreitam horizontes para a juventude. Rede Brasil Atual, jul. 2018. Disponível em: $<$ https://www.redebrasilatual.com.br/trabalho/2018/07/informalidade-e-o-emprego-precario-estreitam-horizontes-para-a-juventude>. Acesso em: 16 dez. 2018.

POMPEU, Renato. O primeiro emprego. In: MINISTÉRIO DA EDUCAÇÃO. Juventude e Trabalho. 2006. Disponível em: $<$ http://portal.mec.gov.br/secad/arquivos/pdf/06 cd al.pdf $>$. Acesso em: 15 dez. 2018.

SANSON, César. Trabalho em Max Weber. Blog Café com Sociologia. 2014. https://www.cafecomsociologia.com/o-conceito-de-trabalho-em-max-weber/. Acesso em: 29 mai. 2019.

SILVA, Thiago Rodrigo da (nome civil de SILVA, Anabella Pavão da). Pratas, grifes, grana e novinhas: adolescências, sociabilidades e ato infracional. Curitiba: CRV, 2016.

SILVEIRA, Daniel; ALVARENGA, Darlan. Falta trabalho para 27,6 milhões de brasileiros, aponta IBGE. G1, ago. 2018. Disponível em: <https://g1.globo.com/economia/noticia/2018/08/16/falta-trabalho-para-276-milhoes-de-brasileiros-aponta-ibge.ghtml>. Acesso em: 18 nov. 2018.

; _. . Desemprego sobre para 12,7\% em março e atinge 13,4 milhões de brasileiros. G1, economia, abr. 2019. Disponível em: https://g1.globo.com/economia/noticia/2019/04/30/desemprego-sobe-para-127percent-em-marco-diz-ibge.ghtml. Acesso em: 29 mai. 2019.

WEBER, Max. A ética protestante e o espírito do capitalismo. Tradução de José Marcos Mariani de Macedo. 6. reimp. São Paulo: Companhia das letras, 2004.

Data de submissão do artigo: Maio de 2019

Data de aceite do artigo: Novembro de 2019 